\title{
POTENCIAL ALELOPÁTICO DO CAPIM-CAMALOTE NA GERMINAÇÃO E NO DESENVOLVIMENTO INICIAL DE ALFACE E CAPIM-COLONIÃO
}

\author{
ZERA, Fabricio Simone ${ }^{1 / 2}$ \\ BETTIOL, João Victor Trombeta ${ }^{1}$ \\ SANT'ANNA, Carla de Barros ${ }^{2}$
}

\begin{abstract}
RESUMO: O potencial alelopático de plantas adquire papel importante no aspecto ecológico, sobretudo em relação à probabilidade de controlar espécies daninhas, sem afetar as culturas agícolas e, sobretudo a produção. Este trabalho teve por objetivo verificar, por meio de testes in vitro, o potencial alelopático do capim-camalote (Rottboellia cochinchinensis) sobre crescimento inicial de plântulas de alface (Lactuca sativa) e capim-colonião (Panicum maximum). $\mathrm{O}$ experimento foi conduzido em casa vegetação, em delineamento inteiramente casualizado, em esquema fatorial $5 \times 2$, com quatro repetições. O primeiro fator foram as concentrações de extrato aquoso de capimcamalote $(0,2,5 ; 5,0 ; 10,0$ e $25,0 \mathrm{mg} / \mathrm{mL})$, e o segundo fator, foram as espécies testadas (alface e capim-colonião). O capim-camalote foi coletado em uma área de infestação para a confecção dos extratos. Cada parcela foi composta por uma placa de Petri onde foram semeadas 20 e 30 as sementes de alface capim-colonião respectivamente com posterior aplicação dos extratos. As variáveis avaliadas foram a germinação e o comprimento da parte aérea e da raiz das plântulas. As sementes de alface tiveram o comprimento da radícula e da parte aérea prejudicados nas concentrações de 10 e $25 \%$, e o capim colonião com $25 \%$. A concentração de $25 \%$ de extrato aquoso de capimcamalote causou a maior inibição da germinação, e interferiu no comprimento da radícula e da parte aérea das plântulas de alface e capim-colonião.
\end{abstract}

Palavras-chave: Rottboellia cochinchinensis. Lactuca sativa. Panicum maximum. Inibidor de crescimento.

SUMMARY: The allelopathic potential of plants acquires an important role in the ecological aspect, especially in relation to the probability of controlling weeds, without affecting the agricultural crops and, especially, the production. This work aimed to verify, by means of in vivo tests, the allelopathic potential of itchgrass (Rottboellia cochinchinensis) on initial growth of lettuce seedlings (Lactuca sativa) and guinea grass (Panicum maximum). The experiment was conducted in greenhouse, with a completely randomized design, in a factorial scheme, with four replications. The first factor was the concentrations of aqueous extract of itchgrass $(0,2.5,5.0,10.0$ and $25.0 \mathrm{mg} \mathrm{mL}$ ${ }^{1}$ ), and the second factor were the test plants (lettuce and guinea grass ). The itchgrass was collected in an infestation area for the preparation of the extracts. Each plot was composed of a Petri dish where 20 and 30 seeds form lettuce and guinea grass were seeded, respectively, with subsequente application of the extracts. The evaluated variables were the germination and the lengths of the aerial part and the root of the seedlings. The lettuce seeds had a radicle and shoot length that were impaired at concentrations of 10 and $25 \%$, and guinea grass at $25 \%$. The concentration of $25 \%$ aqueous extract of itchgrass caused the greatest inhibition of germination, and interfered root and shoot length in both lettuce and guinea grass.

Keywords: Rottboellia cochinchinensis. Lactuca sativa. Panicum maximum. Growth inhibitor.

\section{INTRODUÇÃO}

O termo alelopatia, é originário do grego, onde Allelon significa mútuo e Pathos prejuízos, foi criado por Molish em 1937, como o conjunto de substâncias químicas produzidas pelos seres vivos, que quando exposto no ambiente podem comprometer e/ ou estimular outros indivíduos nos ecossistemas,

\footnotetext{
${ }^{1}$ Universidade Estadual Paulista “Julio de Mesquita Filho" - UNESP/FCAV Jaboticabal.

${ }^{2}$ Instituto Taquaritinguense de Ensino Superior "Dr. Aristides de Carvalho Schlobach" - Faculdade ITES
} 
podendo ser encontrado em plantas superiores, algas, fungos e micro-organismos (SOUZA FILHO; ALVES, 2002). O efeito alelopático pode atuar diretamente, quando a substância interfere no metabolismo vegetal, e/ou indiretamente, quando altera, primeiramente, algumas propriedades do solo, de uma planta sobre a outra, tanto em comunidades naturais como em cultivadas (FERREIRA; AQUILA, 2000).

A pesquisa com compostos alelopáticos vem progredindo nos últimos anos na perspectiva da sua manipulação, para aplicações práticas na agricultura e, assim podendo ser utilizadas no controle de pragas e de plantas daninhas (MAULI et al., 2009). A identificação do potencial alelopático de plantas adquire papel importante no aspecto ecológico, sobretudo em relação à probabilidade de controlar espécies daninhas, um dos principais obstáculos no desenvolvimento de atividades agrícolas (SOUZA FILHO et al., 2009).

Tradicionalmente, para determinação do potencial alelopático de uma planta, tem-se recorrido inicialmente à técnica dos extratos aquosos e orgânicos. Realizada em laboratório e casa de vegetação, esta técnica é considerada a mais simples e usual, fundamentada na capacidade de melhor isolar o efeito alelopático de outras interferências (GOMIDE, 1993). Segundo Medeiros (1989) o solvente mais utilizado nas extrações é a água destilada, pois simula o que acontece na natureza, seguido por solventes orgânicos de vários graus de polaridade.

Várias espécies de plantas daninhas possuem potencial alelopático, tendo eficácia no controle de outras espécies daninhas por meio do uso de compostos alelopáticos obtidos destas como herbicidas, sendo este um processo seguro e eficiente, uma vez que estes produtos são formulados a partir de compostos naturais biodegradáveis e não persistem no meio como poluente (OLIVEIRA JUNIOR; CONSTANTIN, 2001).

O capim-camalote (Rottboellia cochinchinensis [Lour.] W.D. Clayton), é originário da Ásia, possivelmente da Índia, e já se encontra em diversas partes do mundo. É uma planta daninha de extrema importância, afetando pelo menos 18 culturas na África, América Central, América do Sul, Estados Unidos, Austrália e Papua-Nova Guiné (KISSMANN, 1997). No Brasil, ocorre com maior frequência na Região Norte, porém, há focos de sua ocorrência no Estado de São Paulo e na Região Centro-Oeste. Pertencente à família Poaceae, é uma planta muito vigorosa com alto poder prolífico, capaz de emitir até 100 perfilhos e 15000 sementes (SMITH et al., 2001), com capacidade de se manter viável no solo por até quatro anos (LORENZI, 2000), podendo se reproduzir por sementes ou multiplicada através dos fragmentos do caule, que possuem gemas em seus nós (KISSMANN, 1997).

Esta espécie vem se tornando um problema devido a sua alta capacidade de crescimento, habilidade reprodutiva e vigor (CARVALHO et al., 2005), onde suas sementes apresentam uma variabilidade na duração da dormência, dependendo da região (HOLM et al., 1977), e potencial alelopático como mostrados pelos trabalhos de Casini et al. (1998), onde verificaram a atividade inibitória de extratos aquosos de capim-camalote na germinação e crescimento de plântulas de arroz. Kobayashi et al. (2008), relataram sobre o potencial alelopático do pó de capim-camalote incorporado no solo sob condições controladas em plântulas de rabanete (Raphanus sativus).

Essa ciência pode proporcionar excelente oportunidade para impulsionar pesquisas com novas moléculas químicas com propriedades herbicidas destacadas e menores consequências sobre o ambiente e o ser humano do que os compostos sintéticos de uso constante na agricultura (QIMING et al., 2006). Cientes da grande importância das interações alelopáticas entre plantas, neste trabalho procurou-se verificar, por meio de testes in vitro o potencial alelopático do capim-camalote ( $R$. cochinchinensis) sobre o crescimento inicial de plântulas de alface (Lactuca sativa) e capim-colonião (Panicum maximum). 


\section{MATERIAL E MÉTODO}

O desenvolvimento do estudo foi realizado em laboratório, utilizando delineamento experimental inteiramente casualizado em esquema fatorial $5 \times 2$, onde foram testados os tratamentos, concentrações de extrato aquoso de capim-camalote na proporção de $0 \% ; 2,5 \% ; 5,0 \% ; 10 \%$ e $25 \%$ em sementes de alface e de capim-colonião, com quatro repetições.

Para a confecção do extrato bruto $(100 \%)$ do capim-camalote as plantas foram coletadas em área de infestação na cidade de Jaboticabal (SP), de coordenada $4^{\circ} 24^{\prime} 45,04^{\prime \prime}$ 'S e 48 30 '25,91"W, sendo posteriormente levadas ao laboratório para a confecção do extrato.

A partir daí foram separadas $50 \mathrm{~g}$ de folhas de capim-camalote, e essas foram liquidificadas com $150 \mathrm{~mL}$ de água destilada e passada em peneira para a obtenção do extrato. Após esse processo, o extrato foi submetido à filtragem à base de bomba a vácuo, para que somente fosse obtido o extrato líquido da solução.

Após a obtenção do extrato bruto, originaram-se as demais concentrações de extrato do capimcamalote, $0,2,5 ; 5 ; 10$ e $25 \mathrm{mg} \mathrm{mL}^{-1}$ equivalente a $0 \%$ (água destilada); $2,5 \% ; 5,0 \% ; 10 \%$ e $25 \%$ de concentração de extrato em água destilada respectivamente.

Os extratos foram quantificados através da leitura do $\mathrm{pH}$, osmolaridade e condutividade elétrica (CE). Para as leituras utilizou-se osmômetro WESCOR (Modelo 5500), pHmetro e condutivímetro de bancada, respectivamente.

Cada parcela foi representada por uma placa de Petri, nas dimensões de 100 x 15 mm (diâmetro x altura), perfazendo um total de 40 parcelas, sendo 20 parcelas para cada espécie testada. Foram testadas as concentrações (tratamentos) em sementes das plantas teste de alface (Lactuca sativa) e capim-colonião (Panicum maximum), no desenvolvimento inicial. Para que seja indicada como planta teste, a espécie deve apresentar germinação rápida e uniforme, e um grau de sensibilidade que permita expressar os resultados sob baixas concentrações das substâncias alelopáticas (FERREIRA; ÁQUILA, 2000).

As placas de Petri foram revestidas com papel de filtro ( $\mathrm{n}^{\circ}$ 1; Whatman International, Maidstone, Reino Unido) e depois semeadas as sementes de alface e capim-colonião, 20 e 30 sementes respectivamente, em consequência do tamanho das sementes. E por final saturado quatro $\mathrm{mL}$ de extrato solúvel de cada concentrações variáveis $\left(0 ; 2,5 ; 5 ; 10\right.$ e $\left.25 \mathrm{mg} \mathrm{mL}^{-1}\right)$ na respectiva parcela/tratamento (placa de Petri).

As placas de Petri foram acondicionadas na câmara de germinação do tipo B.O.D. (Marconi MA 403) com temperatura ajustada para $30{ }^{\circ} \mathrm{C}$ e fotoperíodo de $12 \mathrm{~h}$. Os papeis de filtro foram constantemente umedecidos com os apropriados extratos, a fim de manter sempre úmidos e não prejudicar a germinação.

De acordo com Inderjit e Dokshini (1995) para estudos de alelopatia os principais parâmetros a serem analisados são a germinação, e o crescimento da parte aérea e radicular. Portanto após sete dias foram avaliados a germinação das sementes e os comprimentos da parte aérea e da raiz das plântulas testadas. Para avaliar a germinação, foi realizada a contagem das plântulas desenvolvidas e depois esses dados foram submetidos ao cálculo da porcentagem de germinação. A avaliação do comprimento foi feito através da medição em papel milimetrado.

Os dados foram submetidos à análise de variância (ANOVA) pelo teste $\mathrm{F}$, e suas médias foram comparadas mediante o teste de Tukey, a $1 \%$ de probabilidade, utilizando o programa estatístico AgroEstat (BARBOSA; MALDONADO, 2010). Quando houve efeito significativo das concentrações e de suas interações, estas foram estudadas pela análise de regressão para melhor compreensão dos resultados obtidos no estudo. 


\section{RESULTADO E DISCUSSÃO}

De acordo com a quantificação dos extratos aquosos de capim-camalote (Tabela 1), a osmolaridade, o pH e a condutividade elétrica, indicam a presença de substâncias químicas, o que observamos que quanto maior a concentração maiores são as concentrações de substâncias químicas presentes.

Tabela 1. Dados da quantificação dos extratos aquosos de capim-camalote, usados no experimento, nas concentrações de $0 ; 2,5 ; 5 ; 10,25$ e $100 \%$.

\begin{tabular}{lccc}
\hline & $\begin{array}{c}\text { Osmolaridade } \\
(\mathrm{mOSm} / \mathrm{L})\end{array}$ & $\mathbf{p H}$ & $\begin{array}{c}\mathbf{C E} \\
(\mathrm{uS} / \mathrm{cm})\end{array}$ \\
\hline Extrato 2,5\% & $99-101$ & 6,68 & 0,15 \\
Extrato 5,0\% & $100-104$ & 6,51 & 0,22 \\
Extrato 10\% & $103-105$ & 6,40 & 0,42 \\
Extrato 25\% & $112-114$ & 6,37 & 0,55 \\
\hline Extrato bruto 100\% & $149-153$ & 6,36 & 1,00 \\
\hline
\end{tabular}

Os dados da germinação das sementes submetidas às diferentes concentrações de extratos (Figura 1) mostraram que as sementes de capim-colonião tiveram menor porcentagem de germinação em relação às sementes de alface. A concentração de $25 \%$ do extrato foi a que mais prejudicou a germinação de ambas as espécies de plantas, alface e capim-colonião.

Figura 1. Porcentagem de germinação das sementes de alface e capim-colonião, tratados com as concentrações de $0 ; 2,5 ; 5 ; 10$ e $25 \%$ de extratos aquosos de Capim-camalote.

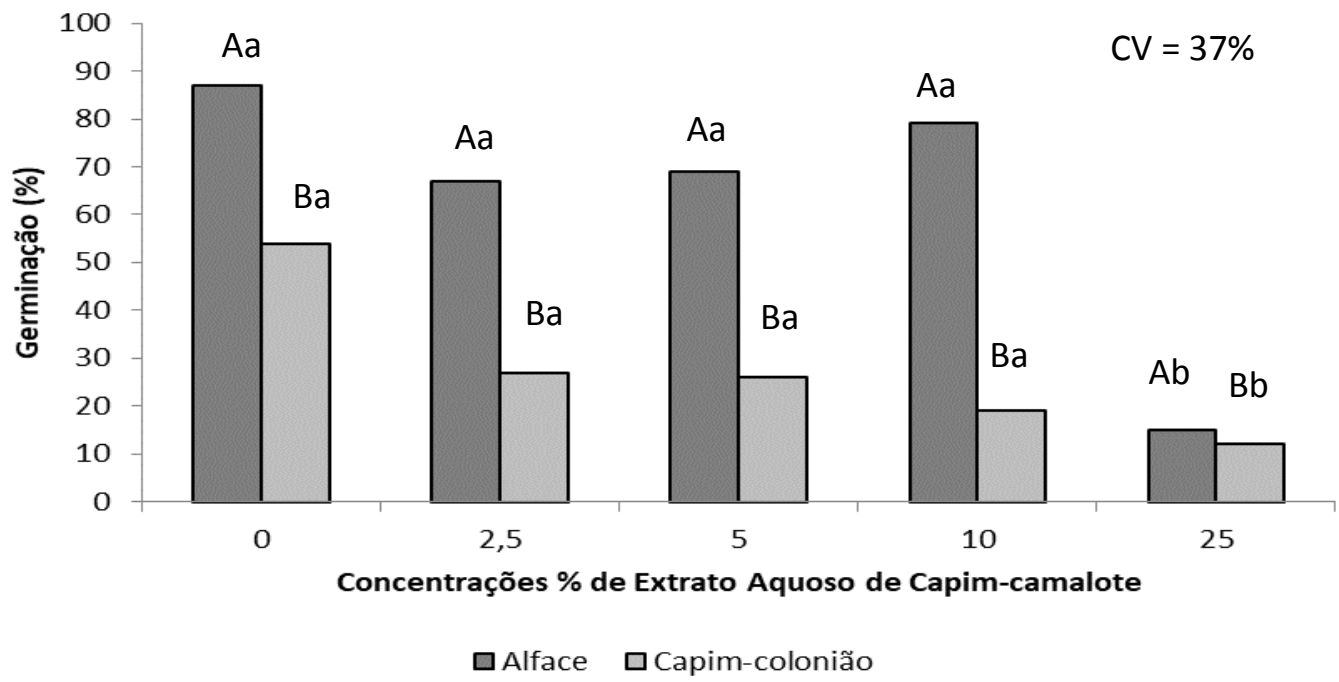

$\mathrm{FC}=6,91 * *, \mathrm{FP}=9,95^{* *}$ e $\mathrm{FCxP}=1,19^{\mathrm{NS}}$. ** significativo a $1 \%$ de probabilidade pelo teste $\mathrm{F}$. Letras minúsculas diferem as concentrações de extrato. Letras maiúsculas indicam espécies de plantas testadas diferentes, estatisticamente pelo teste de Tukey a $1 \%$.

Meksawat e Pornprom (2010) avaliaram a germinação em solo infestado com capim-camalote e solo sem infestação, verificando influência do efeito alelopático em sementes de alface ( $L$. sativa), picão- preto (Bidens pilosa) e capim-arroz (Echinochloa cruz-galli), porém nada foi detectado para as 
sementes de arroz (Oryza sativa).

De acordo com os dados da tabela 2, o extrato aquoso de capim-camalote apresentou-se diferente frente às plantas estudadas (alface e capim-colonião), mas para ambas, os resultados foram significativos $(\mathrm{p} \leq 0,01)$. O desenvolvimento inicial das sementes de alface e capim-colonião teve resposta negativa ao extrato aquoso de capim-camalote na maior concentração, de $25 \%$, em relação às demais, principalmente ao comparado ao controle ( concentração de $0 \%$ ).

Tabela 2. Dados do comprimento da radícula e da parte aérea (mm) das plantas, de alface e capimcolonião, tratados com as concentrações de $0 ; 2,5 ; 5 ; 10$ e $25 \%$ de extratos aquosos de Capim-camalote.

\begin{tabular}{|c|c|c|c|c|c|c|}
\hline \multirow{2}{*}{ Tratamentos } & \multicolumn{3}{|c|}{ Radícula (mm) } & \multicolumn{3}{|c|}{ Parte Aérea (mm) } \\
\hline & Dados originais & \multicolumn{2}{|c|}{ Dados Transf. } & Dados originais & \multicolumn{2}{|c|}{ Dados Transf. } \\
\hline \multicolumn{7}{|l|}{ Concentrações (C) } \\
\hline $0 \%$ & 26,88 & 5,20 & $\mathrm{a}$ & 18,03 & 4,25 & $\mathrm{a}$ \\
\hline $2,5 \%$ & 22,92 & 4,55 & $\mathrm{a}$ & 14,86 & 3,72 & $a b$ \\
\hline $5 \%$ & 26,72 & 5,15 & $\mathrm{a}$ & 21,67 & 4,66 & $\mathrm{a}$ \\
\hline $10 \%$ & 21,99 & 4,69 & $\mathrm{a}$ & 13,84 & 3,69 & $a b$ \\
\hline $25 \%$ & 7,05 & 2,07 & $\mathrm{~b}$ & 8,82 & 2,28 & $\mathrm{~b}$ \\
\hline \multicolumn{7}{|l|}{ Plantas Teste (P) } \\
\hline Alface & 23,27 & 4,45 & $\mathrm{a}$ & 10,67 & 3,08 & $\mathrm{~b}$ \\
\hline Capim-colonião & 18,96 & 4,22 & $\mathrm{a}$ & 20,21 & 4,36 & $\mathrm{a}$ \\
\hline $\mathrm{F}_{\mathrm{C}}$ & \multicolumn{3}{|c|}{$7,36^{* * *}$} & \multicolumn{3}{|c|}{$4,71 * *$} \\
\hline$F_{P}$ & \multicolumn{3}{|c|}{$0,29^{\mathrm{NS}}$} & \multicolumn{3}{|c|}{$11,83^{* *}$} \\
\hline $\mathrm{F}_{\mathrm{CxP}}$ & \multicolumn{3}{|c|}{$0,66^{\mathrm{NS}}$} & \multicolumn{3}{|c|}{$0,03^{\mathrm{NS}}$} \\
\hline $\mathrm{CV}(\%)$ & \multicolumn{3}{|c|}{31,21} & \multicolumn{3}{|c|}{31,54} \\
\hline $\mathrm{dms}_{\mathrm{C}}$ & \multicolumn{3}{|c|}{1,96} & \multicolumn{3}{|c|}{1,70} \\
\hline $\mathrm{dms}_{\mathrm{P}}$ & \multicolumn{3}{|c|}{0,87} & \multicolumn{3}{|c|}{0,76} \\
\hline
\end{tabular}

Dados Transf. - dados transformados raiz $(\mathrm{x}+0,5)$; $* *$ significativo a $1 \%$ de probabilidade pelo teste $\mathrm{F}$. Letras diferentes na coluna diferem estatisticamente pelo teste de Tukey a $1 \%$. CV - coeficiente de variação; dms diferença mínima significativa.

Entre as espécies, o comprimento da radícula não houve diferença significativa, porém com relação aos dados do comprimento da parte aérea verifica-se que a alface foi mais influenciada negativamente no desenvolvimento do que o capim-colonião. Segundo Meksawat e Porprom (2010) cada planta responde particularmente de acordo com as diferentes concentrações de extrato aquoso de capimcamalote, consequentemente devido à interação entre o aleloquímico e a planta estudada, portanto justifica o comportamento diferencial neste estudo para o desenvolvimento inicial da alface e do capim-camalote.

No estudo de Bundit et al. (2016), testando os efeitos alelopáticos do capim-camalote no desenvolvimento inicial de mentrasto (Ageratum conyzoides) e capim-arroz (Echinochloa cruz-galli), os autores relataram que ambas as sementes foram afetadas pelas concentrações de aleloquímicos do capimcamalote (concentrações de 0,01 e 0,1 g. $\mathrm{g}^{-1}$ solo) nos comprimentos da radícula e da parte aérea. Verificando o extrato da folha do perfilho e de raiz de capim-camalote no desenvolvimento inicial de sementes de picão-preto (Bidens pilosa), capim-arroz (E. cruz-galli), arroz (Oryza sativa) e alface ( $L$. 
sativa) observou-se que qualquer tipo de extrato influenciou negativamente no desenvolvimento dessas sementes (Meksawt e Pronprom, 2010). Os autores concluíram que todos os extratos foram significativos no desenvolvimento das sementes estudadas e que cada espécie teve resposta diferente para as concentrações estudadas $\left(5,10,50\right.$ e $\left.10 \mathrm{mg} \mathrm{mL}^{-1}\right)$, enquanto que o picão-preto, alface e arroz foram mais influenciados negativamente para as concentrações de 50 e $100 \mathrm{mg} \mathrm{mL}^{-1}$ tanto para o comprimento da radícula e parte aérea. No caso do capim-arroz foi comprometido com a dose de $100 \mathrm{mg} \mathrm{mL}^{-1}$.

A análise de regressão indicou que o modelo linear apresentou o melhor ajuste em ambas às espécies estudadas, o que indica que é possível estabelecer uma relação funcional entre as concentrações estudadas de extrato aquoso de capim-camalote e o desenvolvimento inicial de alface e capim-colonião.

Quando as sementes de alface foram submetidas às diferentes concentrações do extrato, foram obtidos os comprimentos da radícula e da parte aérea inferior para as concentrações de 10 e $25 \%$, tendo um coeficiente de $\mathrm{R}^{2}=0,9156$ e 0,9926 respectivamente, o que mostrou forte influência nas variáveis em estudo (Figura 2).

Figura 2. Equação estimada das concentrações crescentes de extrato aquoso de capim-camalote no desenvolvimento, comprimento da radícula e parte aérea $(\mathrm{mm})$, de plântulas de alface.
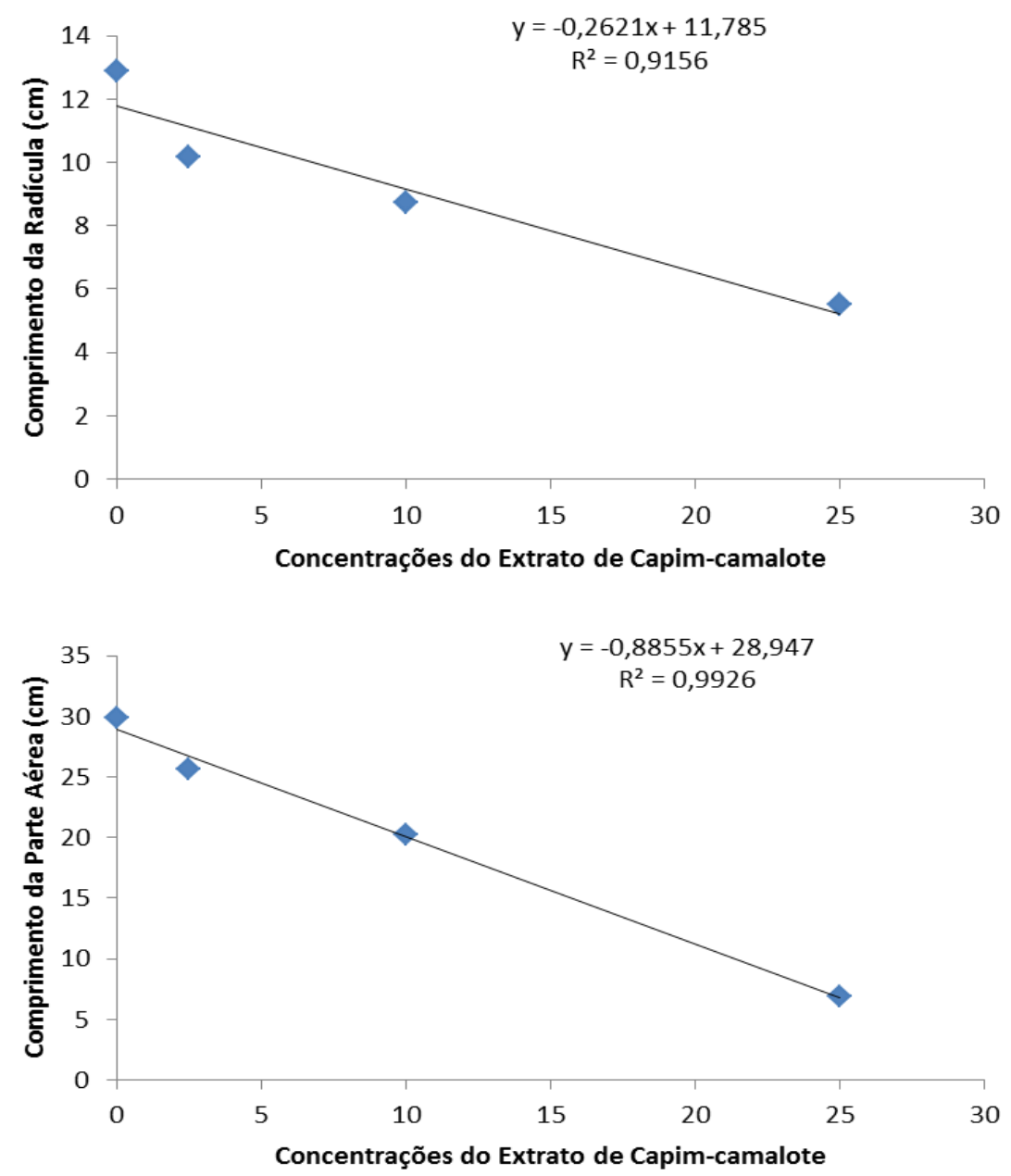

Nos resultados das sementes de capim-colonião para as concentrações do extrato, foram obtidos comprimento da radícula e da parte aérea inferior a concentração de $25 \%$, e o coeficiente de $\mathrm{R}^{2}=$ 0,9334 e 0,9904 respectivamente, o que mostrou também forte influência nessas variáveis (Figura 3). 
Figura 3. Equação estimada das concentrações crescentes de extrato aquoso de capim-camalote no desenvolvimento, comprimento da radícula e parte aérea $(\mathrm{mm})$, de plântulas de capim-colonião.
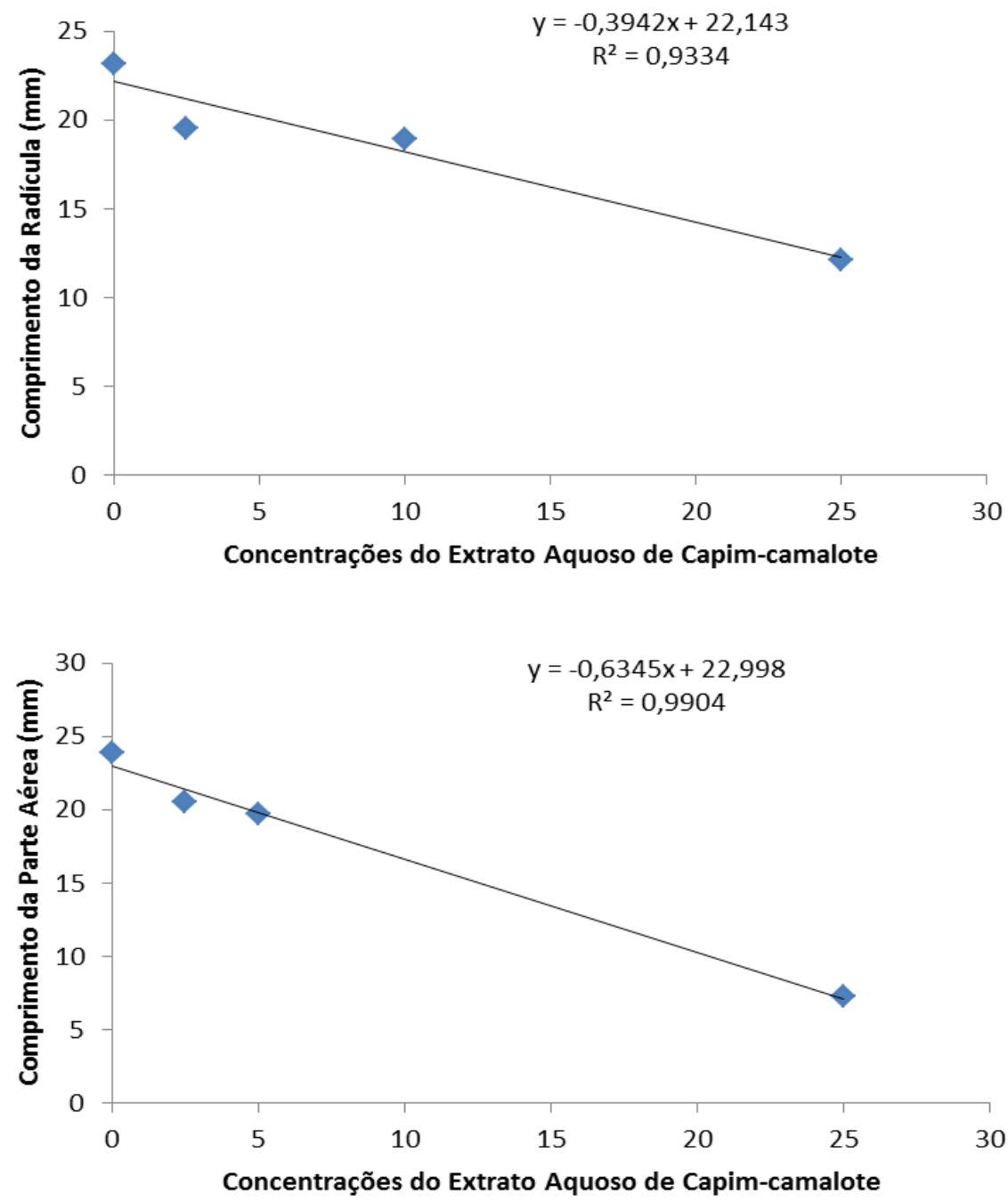

Tais resultados indicam que a parte aérea (folhas) de capim-camalote provavelmente apresenta compostos alelopáticos solúveis em água, que são capazes de inibir a germinação e influenciar o comprimento da radícula e da parte aérea de plântulas de alface e capim-colonião.

\section{CONCLUSÃO}

A concentração de $25 \%$ de extrato aquoso de capim-camalote causou a maior inibição da germinação, e interferiu no comprimento da radícula e da parte aérea das plântulas de alface e capimcolonião.

\section{REFERÊNCIAS}

BARBOSA, J.C.;MALDONADO JUNIOR, W. Agrostat - Sistema para análises estatísticas de ensaios agronômicos. Versão 1.0. Jaboticabal: Departamento de Ciências Exatas, 2010.

BUNDIT, A.; DATTA, A.; PORNPROM, T. Effects of timing and soil moisture on the allelopathic activity of itchgrass (Rottboellia cochinchinensis) in soil. Biological Agriculture \& Horticulture, v. 32, n. 4, p. 269-276. 2016. 
CARVALHO, S.J.P.et al. Crescimento e desenvolvimento da planta daninha capim-camalote. Bragantia, Campinas, v. 64, n. 4, p. 591-600, 2005.

CASINI P., VECCHIO V. TAMANTINI I. Allelopathic interference of itchgrass and cogongrass: Germination and early development of rice. Trop.Agric. (Trinidad) 75, 445-451, 1998.

FERREIRA, A.G.; ÁQUILA, M.E.A. Alelopatia: uma área emergente da ecofisiologia. Revista Brasileira de Fisiologia Vegetal, v.12, p.175-204, 2000.

GOMIDE, M.B. Potencialidades alelopáticas dos restos culturais de dois cultivares de cana-deaçúcar (Saccharum sp), no controle de algumas plantas daninhas. 1993. 96 f. Tese (Doutorado em Fitotecnia) - Escola Superior de Agricultura Luiz de Queiroz, Universidade de São Paulo, Piracicaba, 1993.

HOLM, L.G.et al.The World's Worst Weeds: Distribution and Biology. The University of Hawaii Press, Honolulu, HI, 1977. P. 139-145.

INDERJIT; DAKSHINI, K.M.M. On laboratory bioassays in allelopathy. Botanical Review, v. 61, n. 1, p. 28-44, 1995.

KISSMANN, K.G. Plantas infestantes e nocivas. t.I - Plantas inferiores; monocotiledôneas - 2a . ed. São Paulo: BASF, 1997. 825p.

KOBAYASHI, K.et al. Allelopathic potential of itchgrass (Rottboellia exaltata L. f.) powder incorporated into soil. Weed Biol. Manag. 8, 64-68. 2008.

LORENZI, H. Plantas daninhas do Brasil: terrestres, aquáticas parasitas e tóxicas. 3.ed. Nova Odessa: Plantarum, 2000. $608 \mathrm{p}$.

MAULI, M. M.et al. Alelopatia de Leucena sobre soja e plantas invasoras. Semina: Ciências Agrárias, Londrina, v. 30, n. 1, p. 55-62, jan./mar. 2009.

MEDEIROS, A. R. Determinação de potencialidade alelopáticas em agroecossistemas. 1989. 92 f. Tese (Doutorado em Agronomia) - Escola Superior de Agricultura Luiz de Queiroz, Piracicaba, 1989.

MEKSAWAT, S.; PORNPROM, T. Allelopathic effect of itchgrass (Rottboellia exaltata L.f.) on seed germination and plant growth. Weed Biology and management, v.10, n.14, p.16-24, 2010.

OLIVEIRA JR., R.S.; CONSTANTIN, J. Plantas daninhas e seu manejo. Guaíba Agropecuária, 2001. p. 291-314.

QIMING, X.et al. Allelophatic activity of volatile substance from submerged macrophytes on Microcystin aeruginosa. Acta Ecol. Sinica, v. 26, n. 11, p. 3549-3554, 2006.

SMITH, M. C.et al.Integrated management of itchgrass in a corn cropping system: Modelling the effect of control tactics. Weed Sci., v.49, n. 1, p. 123-134, 2001.

SOUZA FILHO, A.P.S.; ALVES, S.M. Mecanismos de ação dos agentes alelopáticos. In: Souza Filhos, A.P.S.; Alves, S.M. Alelopatia: princípios básicos e aspectos gerais. Belém: Embrapa Amazonia Oriental, 2002, p. 131- 154.

SOUZA-FILHO, A.P. da S.et al. Efeitos potencialmente alelopáticos dos óleos essenciais de Piper hispidinervium C. DC. e Pogostemon heyneanus Benth sobre plantas daninhas. Acta Amazonica, Manaus, v. 39, n. 2, p. 389-395, 2009. 